mỗi vài ngụm sữa hoặc đồ uống.

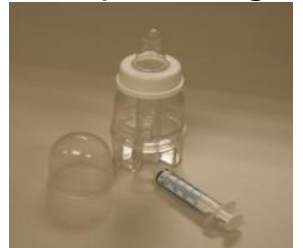

Hinh 4. Binh sữa Medibottle $\mathbb{R}$ (Savi Baby, Mỹ)

"Cốc nuốt viên thuốc" đã được phát triển để giúp những bệnh nhân gặp khó khăn trong việc nuốt viên thuốc. Cốc có nắp đậy và một vòi được thiết kễ đặc biệt. Người dùng đổ đầy nước giải khát vào một nửa cốc, đậy nắp cốc và thả viên thuốc vào vòi. Viên thuốc nằm trên một tấm lưới phía trên chất lỏng. Sau đó người dùng sẽ uống một cách tự nhiên từ cốc. Độ nghiêng và dòng chảy của chất lỏng đẩy viên thuốc xuống phía sau cổ họng để dễ nuốt.

\section{KẾT LUẬN}

Các nhà nghiên cứu phát triển sản phẩm đã ngày càng có nhiều nỗ lực trong việc phát triển các dạng bào chế đường uống dành riêng cho trẻ em. Bên cạnh các dạng thuốc sử dụng ngay như si rô thuổc, hỗn dịch thuốc, viên nén nhỏ, viên nén mini, viên nhai, viên nén phân tán trong miệng, màng phim tan trong miệng còn có các danng thuốc cần phải thao tác trước khi sử dụng như bột hoặc cốm phải pha chế lại thành dung dịch hoặc hỗn dịch, viên sủi bọt, viên nén phân tán trong nước, bột hoặc viên nang chứa bột thuốc dùng để rắc vào thức ăn mềm và đồ uống.

Bên cạnh đó, các nhà nghiên cứu vẫn đang tiếp tục cải tiến trong các chế phẩm dành cho trẻ em qua đường uống. Các biện pháp cải thiện mùi vị của thuốc rắn bằng kỹ thuật tạo hệ tiểu phân nano che vị đắng, đồng kết tinh, bào chế bột thạch hoặc bột sữa chứa dược chất, công nghệ in 3D để bào chế kẹo dẻo chứa dược chất hoặc nghiên cứu các dụng cụ phân liêu thích hợp cho thuốc uống lỏng dùng cho trẻ em.

\section{TÀI LIỆ THAM KHẢO}

1. Almurisi S. H., Doolaanea A. A., et al. (2020), Formulation development of paracetamol instant jelly for pediatric use, Drug development and industrial pharmacy, 46(8), pp. 1373-1383.

2. Comoglu T., Ozyilmaz E.D., (2019), Orally disintegrating tablets and orally disintegrating mini tablets-novel dosage forms for pediatric use, Pharmaceutical Development and technology, 24(7), pp. 902-914.

3. Deng Y., Shen L., Yang Y., et al. (2021), Development of nanoparticle-based orodispersible palatable pediatric formulations, International Journal of Pharmaceutics, 596, pp. 1-9.

4. Meyers R. (2019), A wish list for drug development in pediatrics, Journal of Pharmaceutical Sciences, pp. 1-5.

5. Moreira M., Saraguca M., (2020), How can oral pediatric formulations be improved? A challenge for the XXI century, International Journal of Pharmaceutics, 590, pp. 1-9.

6. Nese C., Palugan L., Cerrea M., et al. (2020), Preparation and characterization of a powder manufactured by spray drying milk based formulations for the delivery of theophylline for pediatric use, International Journal of Pharmaceutics, 580, pp. 1-12.

7. Strickly R. G., (2019), Pediatric oral formulations: An updated review of commercially available pediatric oral formulations since 2007, Journal of Pharmaceutical Sciences, 108, pp. 1335-1365.

8. Tagami T., Ito E., Kida R., et al. (2021), 3D printing of gummy drug formulations composed of gelatin and an HPMC-based hydrogel for pediatric use, International Journal of Pharmaceutics, 594, pp. 1-7.

\title{
BIẾN THIÊN NHIP TIM GIẢM LÀ YẾU TỐ NGUY CƠ XUẤT HIÊ̂N RUNG NHĨ MỚI SAU PHẪU THUÂT CẦU NỐI CHỦ VÀNH
}

TÓM TẮT

Hệ thống thần kinh tự chủ có vai trò như là yếu tố khởi phát và là nguy cở xuất hiện các rối loạn nhịp

${ }^{1}$ Bênh viên Tim Hà Nôi

Bềnh viền 108

${ }^{3}$ Bềnh viền Bach Mai

Chịu trách nhiệm chính: Ngọ Văn Thanh

Email: ngogiahung@gmail.com

Ngày nhâan bài: 4.01.2021

Ngày phản biên khoa hoc: 3.3.2021

Ngày duyệt bài: 16.3.2021
Ngọ Văn Thanh1, Phạm Trường Sơn², Nguyễn Quang Tuấn ${ }^{3}$ và cs.

tim. Rung nhĩ mới xuất hiện sau phẫu thuật câu nối chủ vành có tỉ lệ $5-40 \%$ tùy theo nghiên cứu. Mối liên quan giữa biến thiên nhịp tim với rung nhĩ xuất hiện sau phấu thuật đã được nghiên cứu với các kết quả khác nhau. Vì vậy, chúng tôi tiến hành nghiên cứu này với mục đích tìm hiểu mối liên quan giữa biến thiên nhịp tim giảm trước phẫu thuật với rung nhĩ mới xuất hiện sau phẫu thuật câuu nối chủ vành. Đối tượng và phương pháp nghiên cứu: tiến cứu mô tả theo dõi dọc 119 đối tượng bệnh có nhịp xoang, được phẫu thuât cầu nối chủ vành có tuần hoàn ngoài cớ thể tai Bệnh viện Tim Hà Nội từ 6/2016 đến 8/2018. Theo dối rung nhî̀ và biến thiên nhịp tim bằng Holter điện tim 
24 giờ tại các thời điểm trước phẫu thuật, sau phẫu thuật 7 ngày, 3 tháng và 6 tháng. Kết quả: tỉ lệ rung nhĩ mới xuất hiện sau phẫu thuật 7 ngày $13,7 \%$, sau 3 tháng $13,8 \%$ và sau 6 tháng $17,2 \%$. Tî lệ biến thiên nhịp tim giảm trước phẫu thuật $28,6 \%$, sau 7 ngày $51,8 \%$, sau 3 tháng $19,6 \%$ và sau 6 tháng $12,7 \%$. Biến thiên nhịp tim giảm trước phâuu thuật có nguy cơ xuất hiện rung nhĩ sau phẫu thuật gấp $3-4$ lần. Chỉ số SDNN giảm có giá trị cao nhất liên quan xuất hiện rung nhĩ sau phẫu thuật. Kết luận: Tỉ lệ rung nhĩ mới xuất hiện sau phẫu thuật cầu nối chủ vành 13,7$17,2 \%$ theo dõi đến 6 tháng. Biến thiên nhịp tim giảm là yếu tố nguy cơ xuất hiện rung nhĩ mới sau phẫu thuật cầu nối chủ vành.

Tư khoá: Rung nhĩ, biến thiên nhịp tim, phẫu thuật câuu nối chủ vành.

\section{SUMMARY \\ PREOPERATIVE HEART RATE VARIABILITY PREDICTS ATRIAL FIBRILLATION AFTER CORONARY ARTERY BYPASS GRAFTING}

Introduction and objectives: The autonomic nervous system may play an important role as a trigger and risk marker for developing arrhythmia. The incidence of new-onset atrial fibrillation postoperative coronary artery bypass surgery was $5-40 \%$. The relationship between preoperative heart rate variability and atrial fibrillation after coronary artery bypass surgery has been investigated with divergent results. The purpose of the study was to investigate the association between preoperative heart rate variability and atrial fibrillation after coronary artery bypass graft surgery. Methods: The study involved 119 consecutive patients with coronary artery disease were assessed with 24-hour Holter recordings 2 days before coronary artery bypass grafting and 1 week, 3 months, 6 months after coronary artery bypass grafting at Hanoi Heart Hospital from 6/2016 to 8/2018. Main results: The rate of new on-set atrial fibrillation post coronary artery bypass graft surgery 7 days was $13.7 \%, 13.8 \%$ after 3 months and $17.2 \%$ after 6 months. Low heart rate variability before surgery accounted for $28.6 \%, 51.8 \%$ after 7 days, $19.6 \%$ after 3 months and $12.7 \%$ after 6 months. Decreased heart rate variability before surgery had the risk of developing new-onset atrial fibrillation after surgery 3-4 times. In which, the reduction of SDNN index had the highest value related to atrial fibrillation after surgery. Conclusions: The rate of new onset atrial fibrillation after coronary artery bypass graft surgery from $13.7 \%$ to $17.2 \%$ followed up to 6 months. Decreased heart rate variability was pedict a risk factor for new atrial fibrillation after coronary artery bypass graft surgery.

\section{I. ĐĂT VẤN ĐỀ}

Hệ thông thần kinh tự chủ (TKTC) có vai trò quan trong trong việc duy trì sự ổn định điện thế của tế bào cơ tim, bất thường hệ thống này có thể là nguyên nhân gây rối loạn nhịp (RLN) tim và đột tử. Biến thiên nhịp tim (BTNT) được sử dung rông rãi gián tiếp đánh giá hoat động của hệ thống TKTC trong các bệnh lý tim mạch.
Rung nhĩ (RN) mới xuất hiện sau phẫu thuật cầu nối chủ vành $(\mathrm{CNCV})$ có tỉ lệ từ $5-40 \%$ tùy theo nghiên cứu. Tình trạng RN góp phần làm tăng tỉ lệ tử vong, đột quy và các biến cố huyết khối tắc mạch khác như suy tim, giảm chất lượng sống, giảm hoạt động thể lực và rối loạn chức năng thất trái. Mối liên quan BTNT với RN sau phẫu thuật CNCV đã được nghiên cứu với các kết quả khác nhau, trong đó BTNT giảm là yếu tố có ảnh hưởng tới RN mới xuất hiện sau phẫu thuật. Vì vậy, chúng tôi tiến hành nghiên cứu trên đối tượng bệnh động mạch vành (ĐMV) mạn tính được điều tri phẩu thuât CNCV bằng Holter điên tim đồ (ĐTĐ) 24 giờ với hai mục tiêu: xác định tí lệ rung nhĩ mới xuất hiện sau phẫu thuật, đặc điểm biên thiên nhịp tim giảm và tìm hiêu mối liên quan giữa biến thiên nhip tim giảm trước phẫu thuật với rung nhĩ mới xuất hiện sau phẫu thuật cầu nối chủ vành.

\section{II. ĐỐI TƯợNG VÀ PHƯƠNG PHÁP NGHIÊN CỨU \\ 2.1. Đối tượng nghiên cứu}

Tiêu chuấn lựa chơn: 119 bệnh nhân bệnh ĐMV ổn định được điều trị phẫu thuật CNCV tại Bệnh viện Tim Hà Nội (từ 8/2016 - 8/2018) có nhịp xoang trước phẫu thuật.

Tiêu chuẩn loại trừ: các tình trạng bệnh không đánh giá được BTNT trước phẫu thuật (như: RN, suy nút xoang, block nhĩ thất cấp 2,3 hoặc đang dùng máy tạo nhịp), bệnh nhân phầu thuật CNCV kết hợp phẫu thuật bệnh lý van tim hoặc bệnh tim bẩm sinh, bệnh nhân không đồng ý tham gia nghiên cứu.

2.2. Phương pháp và cách tiến hành nghiên cứu. Nghiên cứu được tiến hành theo phương pháp tiến cứu, mô tả cắt ngang có so sánh trước sau.

Công cụ nghiên cứu: Holter ĐTĐ 24 giờ.

Các bước tiến hành: lần 1 ghi Holter ĐTĐ trước phẫu thuật. Lần 2 ghi Holter ĐTĐ sau phẫu thuật 7 ngày. Lần 3 sau phẫu thuật 3 tháng và lần 4 là sau phẫu thuâat 6 tháng. Chỉ phân tích BTNT ở các bản ghi Holter ĐTÐ có nhịp xoang.

Các chỉ tiêu nghiên cứu và đánh giá: Chỉ số BTNT theo thời gian (ASDNN, SDANN, SDNN, Mean NN, rMSSD và $p$ NN50). Tiêu chuẩn chẩn đoán điện tim theo Minnesota (1982). Chẩn đoán RN cơn khi RN xuất hiện trên bản ghi $\geq 30$ giây, RN 24 giờ khi RN xuất hiện ở toàn bộ bản ghi điện tim. BTNT giảm theo Michel H Crawford khi có hơn một chỉ số biểu lộ BTNT giảm xuống mức giới hạn (bảng 1).

Bảng 1. Giá trị biểu lộ giảm biến thiên nhịp tim 


\begin{tabular}{|c|c|}
\hline Phân tích theo thời gian & BTNT giảm \\
\hline r MSSD & $<15 \mathrm{~ms}$ \\
p NN 50 & $<0,75 \%$ \\
\hline SDNN index (ASDNN) & $<30 \mathrm{~ms}$ \\
\hline SDNN & $<50 \mathrm{~ms}$ \\
SDANN & $<40 \mathrm{~ms}$ \\
\hline
\end{tabular}

Phân tích thống kê được thực hiện trên mềm SPSS 20.0 .

\section{KẾT QUẢ NGHIÊN CỨU}

Bảng 2. Đặc điểm chung, yếu tố nguy cơ và bệnh lý phối hợp

\begin{tabular}{|c|c|c|}
\hline & \multicolumn{2}{|c|}{ Giá trị $(\mathrm{n}=119)$} \\
\cline { 2 - 3 } & $\begin{array}{c}\text { Số beênhh } \\
\text { nhần }\end{array}$ & $\begin{array}{c}\text { Tỉ lệ } \\
\mathbf{( \% )}\end{array}$ \\
\hline Nam giới & 99 & 83,2 \\
\hline Hút thuốc lá & 55 & 46,2 \\
\hline
\end{tabular}

\begin{tabular}{|c|c|c|}
\hline Thừa cân béo phì BMI $\geq 23$ & 61 & 51,26 \\
\hline Tiền sứ nhồi máu cơ tim & 10 & 8,4 \\
\hline Tăng huyết áp (THA) & 103 & 86,6 \\
\hline Rối loạn lipid máu & 62 & 52,1 \\
\hline Bệnh phối mạn tính (COPD) & 4 & 3,4 \\
\hline Đái tháo đường type 2 \\
(ĐTĐ2) & 40 & 33,6 \\
\hline Bệnh động mạch ngoại biên & 15 & 12,6 \\
\hline Suy thận $\geq$ IIIa & 56 & 47,1 \\
\hline Tuổi (năm) & $\begin{array}{c}64,92 \pm 7,34 \\
(38-81)\end{array}$ \\
\hline BMI $\left(\mathrm{kg} / \mathrm{m}^{2}\right)$ & $\begin{array}{c}22,99 \pm 2,85 \\
(15,99-30,8)\end{array}$ \\
\hline EuroSCORE II $(\%)$ & $\begin{array}{c}1,31 \pm 0,82 \\
(0,6-4,9)\end{array}$ \\
\hline
\end{tabular}

THA, rối loạn lipid máu và thừa cân, béo ph có tỉ lệ cao. Nam giới có tỉ lệ cao gấp 4,9 lần nữ.

Bảng 3. Tỉ lệ rôi loạn nhịp trên Holter điện tim trước và sau phẫu thuật

\begin{tabular}{|c|c|c|c|c|c|c|}
\hline & $\begin{array}{l}\text { Trước (1) } \\
\text { phâuu thuâat } \\
(\mathrm{n}=119)\end{array}$ & $\begin{array}{l}\text { Sau (2) } \\
7 \text { ngày } \\
(\mathrm{n}=117)\end{array}$ & $\begin{array}{l}\text { Sau (3) } \\
\mathbf{3} \text { tháng } \\
(\mathrm{n}=116)\end{array}$ & $\begin{array}{l}\text { Sau }{ }^{(4)} \\
\mathbf{6} \text { tháng } \\
(\mathrm{n}=116)\end{array}$ \\
\hline \multirow{5}{*}{$\begin{array}{c}\mathrm{RLN} \\
\text { trên } \\
\text { thất } \\
(\mathrm{n}, \%)\end{array}$} & \multicolumn{2}{|c|}{ Có } & $107(89,9)$ & $102(87,2)$ & $106(91,4)$ & $97(83,6)$ \\
\hline & \multicolumn{2}{|c|}{ Không } & $12(10,1)$ & $15(12,8)$ & $10(8,6)$ & $19(16,4)$ \\
\hline & \multicolumn{2}{|c|}{$p$} & & $\mathrm{p}_{(1-2)}>0,05$ & $\mathrm{p}_{(1-3)}>0,05$ & $\mathrm{p}_{(1-4)}>0,05$ \\
\hline & \multirow{2}{*}{$\mathrm{RN}$} & cơn & $0(0)$ & $16(13,7)$ & $16(13,8)$ & $20(17,2)$ \\
\hline & & 24 giờ & $0(0)$ & $7(6,0)$ & $14(12,1)$ & $14(12,1)$ \\
\hline \multirow{6}{*}{$\begin{array}{c}\text { RLN } \\
\text { thất } \\
(n, \%)\end{array}$} & \multicolumn{2}{|c|}{ NTT thất } & $72(60,5)$ & $97(82,9)$ & $78(67,2)$ & $72(62,1)$ \\
\hline & & & & $\mathrm{p}_{(1-2)<0,05}$ & $\mathrm{p}_{(1-3)}>0,05$ & $\mathrm{p}_{(1-4)}>0,05$ \\
\hline & \multicolumn{2}{|c|}{ cơn nhanh thất } & $3(2,5)$ & $8(6,8)$ & $4(3,5)$ & $1(0,9)$ \\
\hline & \multirow{3}{*}{ Lown } & 0 & $47(39,5)$ & $20(17,1)$ & $38(32,8)$ & $44(37,9)$ \\
\hline & & $1-2$ & $47(39,5)$ & $55(48,0)$ & $57(49,2)$ & $49(42,1)$ \\
\hline & & $\geq 3$ & $25(21,0)$ & $42(35,9)$ & $21(17,2)$ & $23(19,8)$ \\
\hline
\end{tabular}

RN sau phẫu thuât có tỉ lê từ $13,7 \%$ đến $17,2 \%$. Tỉ lê NTT thất và mức độ nă̆ng theo Lown có sứ khác biệt trước và sau phẫu thuật, ổn định sau $3-6$ tháng phẫu thuật.

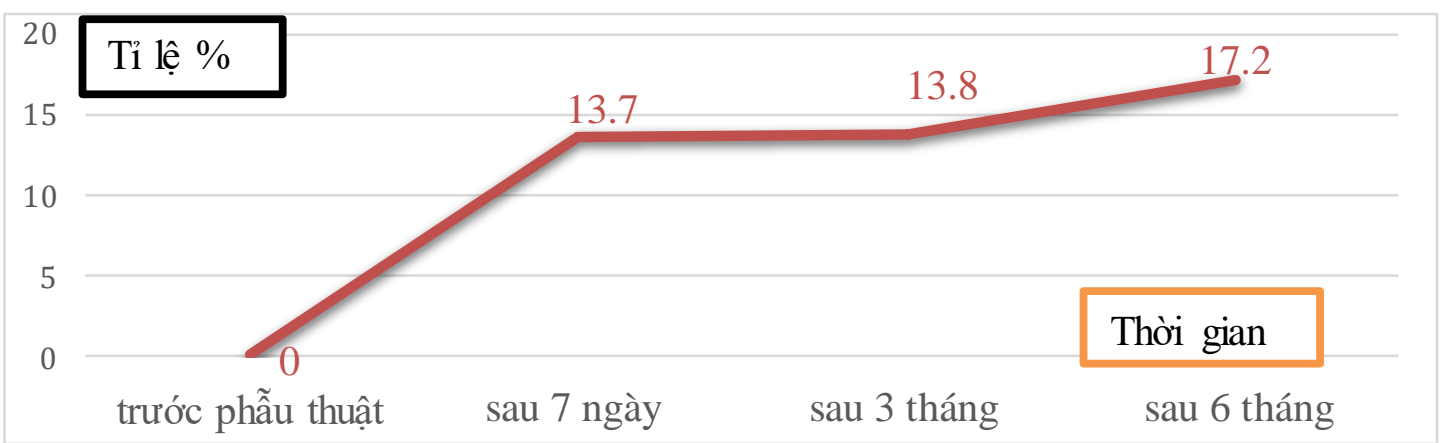

Biểu đồ 1. Đặc điểm tỉ lệ rung nhĩ cơn sau phẫu thuât

Tỉ lệ RN mới xuất hiện tăng dân theo thời gian và cao nhất $17,2 \%$ sau 6 tháng.

Bảng 4. Đặc điểm thay đổi chỉ số biểu lộ biến thiên nhịp tim giảm theo thời gian trước phẫu thuật và sau phẫu thuật

\begin{tabular}{|c|c|c|c|c|}
\hline & $\begin{array}{l}\text { Trước }{ }^{(\mathbf{1})} \text { phâu } \\
\text { thuật }(\mathrm{n}=119)\end{array}$ & $\begin{array}{c}\text { Sauu(2) } 7 \text { ngày } \\
(n=109)\end{array}$ & $\begin{array}{c}\text { Sau }^{(3)} \mathbf{3} \text { tháng } \\
(\mathrm{n}=102)\end{array}$ & $\begin{array}{c}\text { Sau }{ }^{(4)} \mathbf{6} \text { tháng } \\
(n=102)\end{array}$ \\
\hline \multirow{2}{*}{$\begin{array}{c}\text { BTNT giảm } \\
(n, \%)\end{array}$} & $34(28,6)$ & $57(52,3)$ & $20(19,6)$ & $13(12,7)$ \\
\hline & $85(71,4)$ & $52(47,7)$ & $82(80,4)$ & $89(87,3)$ \\
\hline
\end{tabular}


TAP CHÍ Y HỌC VIÊT NAM TẬP 500 - THÁNG 3 - SỐ 2 - 2021

\begin{tabular}{|c|c|c|c|c|c|}
\hline & & & $\mathrm{P}_{(1,2)}<0,001$ & $\mathrm{P}_{(1,3)}<0,05$ & $\mathrm{P}_{(1,4)}>0,05$ \\
\hline \multirow{3}{*}{$\begin{array}{c}\text { ASDNN } \\
(\mathrm{ms})\end{array}$} & $<30$ & $23(19,3)$ & $50(45,9)$ & $14(13,7)$ & $6(5,9)$ \\
\hline & $\geq 30$ & $96(80,7)$ & $59(54,1)$ & $88(86,3)$ & $96(94,1)$ \\
\hline & $p$ & & $p_{(1,2)}<0,05$ & $\mathrm{p}_{(1,3)}>0,05$ & $\mathrm{p}_{(1,4)}>0,05$ \\
\hline \multirow{3}{*}{$\begin{array}{c}\text { rMSSD } \\
\left(\mathrm{ms}^{2}\right)\end{array}$} & $<15$ & $18(15,1)$ & $28(25,7)$ & $10(9,8)$ & $7(6,9)$ \\
\hline & $\geq 15$ & $101(84,9)$ & $81(74,3)$ & $92(90,2)$ & $95(93,1)$ \\
\hline & $p$ & & $\mathrm{p}_{(1,2)}>0,05$ & $\mathrm{p}_{(1,3)}>0,05$ & $\mathrm{p}_{(1,4)}>0,05$ \\
\hline \multirow{3}{*}{$\begin{array}{c}\text { pNN } 50 \\
(\%)\end{array}$} & $<0,75$ & $26(21,8)$ & $34(31,2)$ & $13(12,7)$ & $11(10,8)$ \\
\hline & & $93(78,2)$ & $75(68,8)$ & $89(87,3)$ & $91(89,2)$ \\
\hline & $p$ & & $\mathrm{p}_{(1,2)}>0,05$ & $\mathrm{p}_{(1,3)}>0,05$ & $\mathrm{P}_{(1,4)}>0,05$ \\
\hline \multirow{3}{*}{$\begin{array}{c}\text { SDNN } \\
(\mathrm{ms})\end{array}$} & $<50$ & $10(8,4)$ & $23(21,1)$ & $2(2,0)$ & $1(1,0)$ \\
\hline & $\geq 50$ & $109(91,6)$ & $86(78,9)$ & $100(98,0)$ & $101(99,0)$ \\
\hline & $p$ & & $\mathrm{P}_{(1,2)}<0,05$ & $\mathrm{p}_{(1,3)}>0,05$ & $\mathrm{p}_{(1,4)}>0,05$ \\
\hline \multirow{3}{*}{$\begin{array}{l}\text { SDANN } \\
(\mathrm{ms})\end{array}$} & $<40$ & $6(5,0)$ & $22(20,2)$ & $2(2,0)$ & $1(1,0)$ \\
\hline & $\geq 40$ & $113(95,0)$ & $87(79,8)$ & $100(98,0)$ & $101(99,0)$ \\
\hline & $p$ & & $\mathrm{p}_{(1,2)}>0,05$ & $\mathrm{p}_{(1,3)}>0,05$ & $\mathrm{p}_{(1,4)}>0,05$ \\
\hline
\end{tabular}

Đăc điêm BTNT giảm tại các thời điếm: trước phâuu thuật $(28,6 \%)$, sau 7 ngày $(51,8 \%)$, sau 3 tháng $(19,6 \%)$ và sau sáu tháng $(12,7 \%)$. Sau phâu thuật 7 ngày, các chỉ số ASDNN, SDNN có tỉ lệ thay đổi nhiều nhất.

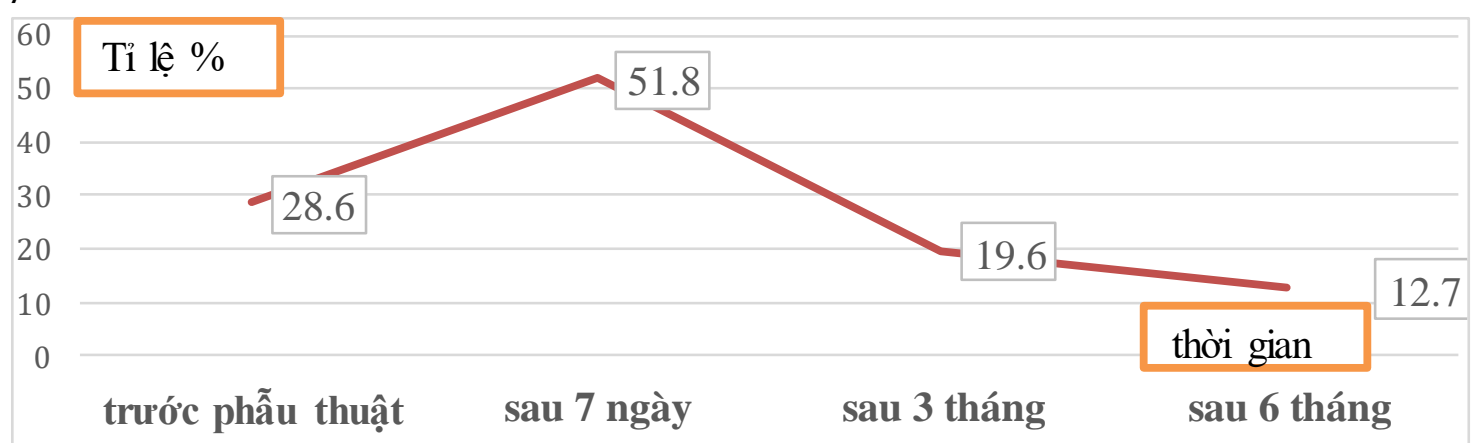

Biểu đồ 2. Đặc điểm tỉ lệ biến thiên nhịp tîn giảm trước và sau phẫu thuật

BTNT giảm có tỉ lệ cao nhất trên $50 \%$ sau 7 ngày phẫu thuật CNCV.

Bảng 5. Mối liên quan giữa biến thiên nhịp tim giảm trước phẫu thuật với sự xuất hiện rung nhĩ mới sau phẫu thuật

\begin{tabular}{|c|c|c|c|c|c|c|c|}
\hline & \multicolumn{2}{|c|}{ BTNT giảm (\%) } & \multirow{2}{*}{ OR } & \multirow{2}{*}{$95 \%(C I)$} & \multirow{2}{*}{$\mathbf{p}$} \\
\hline & & & Có & Không & & & \\
\hline \multirow{4}{*}{$\begin{array}{c}\text { Sau } 7 \\
\text { ngày } \\
(\mathrm{n}= \\
117)\end{array}$} & \multirow{2}{*}{ RN cơn } & Có & $8(24,2)$ & $8(9,5)$ & \multirow{2}{*}{3,04} & \multirow{2}{*}{$1,03-8,94$} & \multirow{2}{*}{$<0,05$} \\
\hline & & Không & $25(75,8)$ & $76(90,5)$ & & & \\
\hline & \multirow{2}{*}{$\begin{array}{c}\text { RN } \\
24 \text { giờ }\end{array}$} & Có & $5(15,2)$ & $2(2,4)$ & \multirow{2}{*}{7,32} & \multirow{2}{*}{$1,34-39,87$} & \multirow{2}{*}{$<0,05$} \\
\hline & & Không & $28(84,8)$ & $82(97,6)$ & & & \\
\hline \multirow{3}{*}{$\begin{array}{c}\text { Sau } 3 \\
\text { tháng } \\
(n=116)\end{array}$} & \multirow{2}{*}{ RN cơn } & Có & $9(28,1)$ & $7(8,3)$ & \multirow{2}{*}{4,30} & \multirow{2}{*}{$1,44-12,82$} & \multirow{2}{*}{$<0,05$} \\
\hline & & Không & $23(71,9)$ & $77(91,7)$ & & & \\
\hline & RN 24 giờ & Có & $8(25,0)$ & $6(7,1)$ & 4,33 & $1,36-13,72$ & $<0,05$ \\
\hline \multirow{4}{*}{$\begin{array}{c}\text { Sau } 6 \\
\text { tháng } \\
(\mathrm{n}= \\
116)\end{array}$} & \multirow{2}{*}{ RN cơn } & Có & $\frac{24(10,0)}{9(28,1)}$ & $11(13,1)$ & \multirow[b]{2}{*}{2,59} & \multirow{2}{*}{$0,95-7,04$} & \multirow[b]{2}{*}{$>0,05$} \\
\hline & & Không & $23(71,9)$ & $73(86,9)$ & & & \\
\hline & \multirow{2}{*}{ RN 24 giờ } & Có & $7(21,9)$ & $7(8,3)$ & \multirow{2}{*}{3,08} & \multirow{2}{*}{$0,98-9,63$} & \multirow{2}{*}{$<0,05$} \\
\hline & & Không & $25(78,1)$ & $77(91,7)$ & & & \\
\hline
\end{tabular}

BTNT giảm trước phẫu thuật, có nguy cơ xuất hiện RN cơn và RN kéo dài 24 giờ sau phẩu thuật 7 ngày gấp $3-7$ lần, sau 3 tháng phẫu thuật gấp 4 lần, sau 6 tháng phẫu thuật gấp 3 lần.

Bảng 6. Môi liên quan giữa chi số biểu lộ biến thiên nhịp tim giảm trước phẫu thuật với sử xuât hiện rung nhĩ 24 giờ sau phẫu thuật 7 ngày 


\begin{tabular}{|c|c|c|c|c|c|c|}
\hline \multirow{2}{*}{\multicolumn{2}{|c|}{ Trước phẫu thuật }} & \multicolumn{2}{|c|}{$\begin{array}{c}\text { Sau phâu thuật } \\
7 \text { ngày }(\%)\end{array}$} & \multirow[t]{2}{*}{ OR } & \multirow[t]{2}{*}{$95 \%(C I)$} & \multirow[t]{2}{*}{$\mathbf{p}$} \\
\hline & & RN & Khống RN & & & \\
\hline \multirow{2}{*}{$\begin{array}{l}\text { ASDNN } \\
(n=117)\end{array}$} & $<30(\mathrm{~ms})$ & $4(57,1)$ & $18(16,4)$ & \multirow{2}{*}{6,81} & \multirow{2}{*}{$1,40-33,08$} & \multirow{2}{*}{$<0,05$} \\
\hline & $\geq 30(\mathrm{~ms})$ & $3(42,9)$ & $92(83,6)$ & & & \\
\hline \multirow{2}{*}{$\begin{array}{c}\text { rMSSD } \\
(n=117)\end{array}$} & $<15\left(\mathrm{~ms}^{2}\right)$ & $5(71,4)$ & $12(10,9)$ & \multirow{2}{*}{20,41} & \multirow{2}{*}{$3,56-117,01$} & \multirow{2}{*}{$<0,001$} \\
\hline & $\geq 15\left(\mathrm{~ms}^{2}\right)$ & $2(28,6)$ & $98(89,1)$ & & & \\
\hline \multirow{2}{*}{$\begin{array}{l}\text { pNN 50 } \\
(n=117)\end{array}$} & $<0,75(\%)$ & $5(71,4)$ & $20(18,2)$ & \multirow{2}{*}{11,25} & \multirow{2}{*}{$2,03-62,19$} & \multirow{2}{*}{$=0,001$} \\
\hline & $\geq 0,75(\%)$ & $2(28,6)$ & $90(81,8)$ & & & \\
\hline \multirow{2}{*}{$\begin{array}{c}\text { SDNN } \\
(n=117)\end{array}$} & $<50(\mathrm{~ms})$ & $4(57,1)$ & $5(4,5)$ & \multirow{2}{*}{28,0} & \multirow{2}{*}{$4,88-160,35$} & \multirow{2}{*}{$<0,001$} \\
\hline & $\geq 50$ (ms) & $3(42,9)$ & $105(95,5)$ & & & \\
\hline \multirow{2}{*}{$\begin{array}{l}\text { SDANN } \\
(\mathrm{n}=117)\end{array}$} & $<40(\mathrm{~ms})$ & $3(42,9)$ & $2(1,8)$ & \multirow{2}{*}{40,5} & \multirow{2}{*}{$5,22-314,19$} & \multirow{2}{*}{$<0,001$} \\
\hline & $\geq 40(\mathrm{~ms})$ & $4(57,1)$ & $108(98,2)$ & & & \\
\hline
\end{tabular}

Bệnh nhân có một trong các chỉ số biếu lộ BTNT giảm trước phầu thuật có nguy cơ xuất hiện RN kéo dài 24 giờ sau 7 ngày tăng gấp $6-40$ lần $(p<0,05)$. Chỉ số SDANN và SDNN có giá trị liên quan xuất hiện RN cao nhất (gấp $28-40$ lần).

Bảng 7. Môi liên quan giữa chỉ số biểu lộ biên thiên nhịp tim giảm trước phẫu thuật với sự xuât hiện rung nhĩ 24 giờ sau phẫu thuật 3 tháng

\begin{tabular}{|c|c|c|c|c|c|c|}
\hline \multirow{2}{*}{\multicolumn{2}{|c|}{ Trước phẫu thuật }} & \multicolumn{2}{|c|}{ Sau phâu thuật 3 tháng (\%) } & \multirow{2}{*}{ OR } & \multirow{2}{*}{ 95\% (CI) } & \multirow{2}{*}{$\mathbf{p}$} \\
\hline & & RN & Không RN & & & \\
\hline \multirow{2}{*}{$\begin{array}{l}\text { ASDNN } \\
(n=116)\end{array}$} & $<30(\mathrm{~ms})$ & $7(50,0)$ & $14(13,7)$ & \multirow{2}{*}{6,28} & \multirow{2}{*}{$1,91-20,65$} & \multirow{2}{*}{$=0,001$} \\
\hline & $\begin{array}{l}\geq 3 \\
<1\end{array}$ & $\begin{array}{l}7(50,0) \\
5(35,7)\end{array}$ & $\begin{array}{l}88(86,3) \\
11(10,8)\end{array}$ & & & \\
\hline $\begin{array}{l}\text { rMSSD } \\
(n=116)\end{array}$ & $\geq 15$ & $9(64,3)$ & $\begin{array}{l}11(10,0) \\
91(89,2)\end{array}$ & 4,59 & $1,30-16,19$ & $<0,05$ \\
\hline $\begin{array}{l}\text { pNN 50 } \\
(n=116)\end{array}$ & $<0,75(\%)$ & $5(35,7)$ & $19(18,6)$ & \multirow{2}{*}{2,42} & \multirow{2}{*}{$0,73-8,07$} & \multirow{2}{*}{$>0,05$} \\
\hline \multirow{2}{*}{$\begin{array}{c}\text { SDNN } \\
(n=116)\end{array}$} & & $\begin{array}{l}9(64,3) \\
5(35,7)\end{array}$ & $\frac{83(81,4)}{3(2,9)}$ & & & \\
\hline & $\geq$ & $9(64,3)$ & $99(97,1)$ & $\begin{array}{c}18,3 \\
3\end{array}$ & $3,75-89,51$ & $<0,001$ \\
\hline \multirow{2}{*}{ SDANN } & $<40(\mathrm{~ms})$ & $2(14,3)$ & $3(2,9)$ & \multirow[t]{2}{*}{5,5} & \multirow[t]{2}{*}{$0,83-36,29$} & \multirow{2}{*}{$=0,05$} \\
\hline & $\geq 40(\mathrm{~ms})$ & $12(85,7)$ & $99(97,1)$ & & & \\
\hline
\end{tabular}

Bệnh nhân có một trong các chỉ số ASDNN, rMSSD, SDNN, SDANN giảm trước phẫu thuật, nguy cơ xuất hiện RN kéo dài 24 giờ sau 3 tháng gấp $4-18$ lần. SDNN giảm có giá trị liên quan xuất hiện RN cao nhất (gấp 18 lần).

Bảng 8. Môi liên quan giữa chỉ số biểu lọ biến thiên nhịp tim giảm trước phẫu thuật với sự xuất hiện rung nhĩ 24 giờ sau phẫu thuật 6 tháng

\begin{tabular}{|c|c|c|c|c|c|c|}
\hline \multirow{2}{*}{\multicolumn{2}{|c|}{ Trước phẫu thuật }} & \multicolumn{2}{|c|}{ Sau phâu thuật 6 tháng $(n, \%)$} & \multirow{2}{*}{ OR } & \multirow{2}{*}{$95 \%(C I)$} & \multirow{2}{*}{$\mathbf{p}$} \\
\hline & & RN & Không RN & & & \\
\hline \multirow{2}{*}{$\begin{array}{l}\text { ASDNN } \\
(n=116)\end{array}$} & $<30(\mathrm{~ms})$ & $6(42,9)$ & $15(14,7)$ & \multirow[b]{2}{*}{4,35} & \multirow{2}{*}{$1,32-14,32$} & \multirow{2}{*}{$=0,01$} \\
\hline & $\geq 30(\mathrm{~ms})$ & $8(57,1)$ & $87(85,3)$ & & & \\
\hline \multirow{2}{*}{$\begin{array}{l}\text { rMSSD } \\
(n=116)\end{array}$} & $<15\left(\mathrm{~ms}^{2}\right)$ & $3(21,4)$ & $13(12,7)$ & \multirow{2}{*}{1,86} & \multirow{2}{*}{$0,45-7,59$} & \multirow{2}{*}{$>0,05$} \\
\hline & $\geq 15\left(\mathrm{~ms}^{2}\right)$ & $11(78,6)$ & $89(87,3)$ & & & \\
\hline \multirow{2}{*}{$\begin{array}{l}\text { pNN 50 } \\
(n=116)\end{array}$} & $<0,75(\%)$ & $4(28,6)$ & $20(19,6)$ & \multirow{2}{*}{1,64} & \multirow{2}{*}{$0,46-5,77$} & \multirow{2}{*}{$>0,05$} \\
\hline & $\geq 0,75(\%)$ & $10(71,4)$ & $82(80,4)$ & & & \\
\hline \multirow{2}{*}{$\begin{array}{c}\text { SDNN } \\
(n=116)\end{array}$} & $<50(\mathrm{~ms})$ & $4(28,6)$ & $4(3,9)$ & \multirow{2}{*}{9,8} & \multirow{2}{*}{$2,12-45,30$} & \multirow{2}{*}{$=0,001$} \\
\hline & $\geq 50$ (ms) & $10(71,4)$ & $98(96,1)$ & & & \\
\hline \multirow{2}{*}{$\begin{array}{l}\text { SDANN } \\
(n=116)\end{array}$} & $<40(\mathrm{~ms})$ & $2(14,3)$ & $3(2,9)$ & \multirow{2}{*}{5,5} & \multirow{2}{*}{$0,83-36,29$} & \multirow{2}{*}{$=0,05$} \\
\hline & $\geq 40(\mathrm{~ms})$ & $12(85,7)$ & $99(97,1)$ & & & \\
\hline
\end{tabular}

Bệnh nhân có một trong các chỉ số ASDNN, SDNN, SDANN giảm trước phầu thuật, nguy cơ xuất hiện RN kéo dài 24 giờ sau 6 tháng tăng gấp $4-9$ lần, SDNN giảm có giá tri liên quan cao nhất ( 9 lânn).

Bảng 9. Phân tích đa biến với sự xuất hiện rung nhĩ cớn sau phấu thuật cầu nối chủ vành Yếu tố nguy cơ

\section{Vớl run \\ 1. Với rung nhĩ sau 3 tháng $(n=116)$}

Đái tháo đường type II Euroscore $\geq 3 \%$ CI 95\%

\begin{tabular}{c|c|c|c}
$-0,44$ & 0,64 & $0,17-2,41$ & $>0,05$ \\
\hline 2,28 & 9,82 & $1,77-54,39$ & $<\mathbf{0 , 0 5}$ \\
\hline
\end{tabular}


TẠP CHÍ Y HOC VIÊT NAM TẠP 500 - THÁNG 3 - SỐ 2 - 2021

\begin{tabular}{|c|c|c|c|c|}
\hline BTNT giảm trước phâu thuật & 1,49 & 4,45 & $1,38-14,33$ & $<\mathbf{0 , 0 5}$ \\
\hline Hằng số & $-4,15$ & & & \\
\hline \multicolumn{2}{|c|}{$\mathbf{2 . ~ V o ̛ ́ i ~ r u n g ~ n h i ̃ ~ s a u ~ 6 ~ t h a ́ n g ~ ( n = 1 1 6 ) ~}$} \\
\hline Tiếu đường & $-1,78$ & 0,16 & $0,03-0,80$ & $<\mathbf{0 , 0 5}$ \\
\hline Euroscore $\geq 3 \%$ & 1,13 & 3,10 & $0,59-16,22$ & $>0,05$ \\
\hline Giảm BTNT trước phâu thuật & 1,08 & 2,96 & $1,02-8,58$ & $<\mathbf{0 , 0 5}$ \\
\hline Hằng số & 0,779 & & & \\
\hline
\end{tabular}

Chú thích: số bệnh nhân RN cơn sạu 3 tháng, 6 tháng ( $n=116:$ missing: 3 tử vong)

Bệnh nhân có BTंNT giảm trước phâ̂u thuật, nguy cơ xuất hiện RN cơn sau 3 tháng cao gấp 4,4 lần, sau 6 tháng cao gấp 2,9 lần.

\section{BÀN LUẬN}

4.1. Đặc điểm của nhóm nghiên cứu. Nhóm nghiền cứu gồm 119 đối tượng bệnh ĐMV mạn tính, trong đó tất cả các đối tượng này đều có nhịp xoang trên Holter ĐTĐ trước phẫu thuật. Sau phẫu thuật 7 ngày có 2 trường hợp tử vong và 7 trường hợp xuất hiện rung nhĩ kéo dài 24 giờ (không đánh giá BTNT). Sau phẫu thuật 3 tháng và 6 tháng có 14 trường hợp rung nhĩ kéo dài 24 giờ và thêm 1 trường hợp tử vong (không đánh giá BTNT).

Nam giới có số lượng lớn hơn gấp hơn 4 lần nữ giới, chiếm tỉ lệ $83,2 \%$ (bảng 2 ). Tỉ lệ này tương tự trong các nghiên cứu về bệnh lý ĐMV trên thể giới và tại Việt Nam. Tuổi tác là một trong những YTNC bênhh lý tim mạch. Độ tuổi có nguy cơ bị bệnh ĐMV đối với nam giới từ 45, nữ giới từ 55 tuổi trở lên. Trung bình độ tuổi trong nghiên cứu của chúng tôi là $64,92 \pm 7,34$ tuổi. Độ tuổi hay gặp là từ $60-70$, thấp nhất là 38, cao nhất là 81 (bảng 2). Vũ Trí Thành (2014), tuổi trung bình là $63 \pm 10,02$ tuổi, trong đó tuổi dưới 70 chiếm tỉ lề $68,7 \%$, trên 70 chiếm tỉ lệ $31,3 \%$. Kết quả này phản ánh đặc điểm chung của bệnh ĐMV là tuổi cao, nhiều YTNC và bệnh lý phối hợp.

4.2. Tỉ lệ rung nhĩ và biến thiên nhịp tim giảm. Do không đủ dữ liệu để kết luận rung nhî sau phẫu thuật là bền bỉ, dai dẳng và mạn tính vì vậy chúng tôi tạm chia ra 2 nhóm là rung nhĩ cớn là tất cả các trường hợp có rung nhĩ trên Holter ĐTÐ có thời gian $\geq 30$ giây và rung nhĩ 24 giờ là các trường hợp rung nhĩ kéo dài trên toàn bộ bản ghi Holter. RN mới xuất hiện và tăng lên theo thời gian sau phẫu thuật CNCV, từ không có RN trước phẫu thuật tăng lền $13,7 \%$ sau 7 ngày, $13,8 \%$ sau 3 tháng và $17,2 \%$ sau 6 tháng (bảng 3 , biểu đồ 1 ). Kết quả này tương tự các nghiên cứu trong nước và quốc tế. Nguyến Anh Dũng (2015) tî lệ này là $16,5 \%$, Abdel-Salam (2017) $10,4 \%$, Sahin (2014) 16,1\%, Tình trạng RN góp phân làm tăng tỉ lệ tử vong, đột quỵ và các biến cố huyết khối tắc mạch khác như suy tim, giảm chất lượng sống, giảm hoạt động thể lực.
Tình trạng RN là nguyên nhân và là YTNC gây đột quy não. Khoảng $10 \%$ bênh nhân RN sau phẫu thuật CNCV bị đột quy não. Đột quy do RN có thể dự phòng được, đây là điều rất quan trọng, thể hiện vai trò tích cực của y học trong điều tri dự phòng. Đối với BMV đã được tái cấp máu bằng phẫu thuật $\mathrm{CNCV}$ vấn đề dùng thêm chống đông kháng vitamin $K$ còn nhiều tranh luận do trong khuyến cáo điều trị sau phẫu thuật CNCV đã có ít nhất 1 thuốc kháng tiểu cầu. Theo Schulman (2015), lợi ích của thuốc kháng đông sớm trong dự phòng đột quy trong RN sau phẫu thuật CNCV là không chắc chắn. Tuy nhiên, khuyến cáo gần đây nhất (2020) cho thấy lợi ích rõ dàng của wafarin (giảm $64 \%$ nguy cơ đột quy và $26 \%$ tỷ lệ tử vong), các thuốc chống đông thế hệ mới như apixaban, dabigatran, edoxaban và rivaroxaban có nhiều ưu điểm và không thua kém warfarin trong việc ngăn ngừa đột quy, đồng thời có liên quan đến việc giảm đáng kể tỳ lệ tử vong do mọi nguyên nhân (giảm $10 \%$ ).

Chúng tôi sử dụng các chỉ số BTNT theo thời gian bao gồm ASDNN, SDANN, SDNN, Mean NN, rMSSD và $\mathrm{p}$ NN50 để nghiên cứu. BTNT giảm được xác định khi ít nhất một trong các chỉ số trên thỏa mãn điều kiên (bảng 1). Trong nghiên cứu này (bảng 4, biểu đồ 2), thay đổi BTNT giảm tại các thời điểm: trước phẫu thuật $(28,6 \%)$, sau phẫu thuật 7 ngày $(51,8 \%)$, sau phấu thuật 3 tháng $(19,6 \%)$ và sau phấu thuật 6 tháng $(12,7 \%)$. Sau phẫu thuật 7 ngày, các chỉ số ASDNN, SDNN có tî lệ thay đổi nhiều nhất. Điều này cũng phù hợp với các phân tích ở trên về đặc điểm giảm BTNT chủ yếu phản ánh giảm cả TKGC và TKPCG. Nhận định về hậu quả BTNT giảm trên đối tượng bệnh ĐMV được điều trị tái tưới máu bằng phẩu thuật có nhiều ý kiến trái chiêu. Milicevic (2004), nghiên cứu BTNT trên 175 đối tượng (124 NMCT và 51 phẫu thuật CNCV) cho rằng: BTNT giảm ở nhóm phẫu thuật CNCV ít có giá trị tiên lượng tử vong hơn nhóm NMCT. Tuy nhiên, BTNT giảm sau phẫu thuật vẫn được các tác giả đánh giá là chỉ điểm biển cố tim mạch sau phẫu thuật. Các nghiên cứu 
khác cũng chỉ ra rằng mất cân bằng trong hệ thống TKTC làm tăng nguy cơ RLN tim ở bệnh nhân bị bệnh ĐMV.

4.3. Biến thiên nhịp tim giảm với sự xuất hiện rung nhĩ mới. BTNT giảm trước phẫu thuật CNCV có liên quan xuất hiện RN cơnn, và $R N$ kéo dài 24 giờ sau phẫu thuật (bảng 5). Bệnh nhân có BTNT giảm trước phẩu thuật, nguy cơ xuất hiện $R N$ cơn và $R N$ kéo dài $\geq 24$ giờ sau phẫu thuật 7 ngày gấp $3-7$ lần, sau 3 tháng phẫu thuật gấp 4 lần. Bệnh nhân BTNT giảm trước phẫu thuật, nguy cở xuất hiện RN kéo dài $\geq 24$ giờ sau 6 tháng phẫu thuật gấp 3 lần. Kết quả này của chúng tôi tương tự nghiên cứu của Takeshi Kinoshita (2011), tỉ lệ RN mới chiếm $25 \%$ sau phẫu thuâtt CNCV. Những đối tượng không bị RN có sự thay đổi BTNT ít hơn đáng kể so với đối tượng xuất hiện RN sau phẫu thuật, với giá trị trung bình là 91 so với 121 đối với SDNN và 19 so với 25 đối với rMSSD. Park (2014), nhận định BTNT giảm trước phẫu thuật có giá trị tiện lượng xuất hiện RN mới và đột quy. não sau phẫu thuật CNCV. Theo Shimony (2014), Ashes (2014) chức năng tim là một yếu tố dự báo về RN mới xuất hiên sau phẫu thuật CNCV.

Phân tích đa biến sau 3 tháng, 6 tháng phẫu thuật (bảng 9), cùng các YTNC nếu bệnh nhân có BTNT giảm trước phẫu thuật có nguy cơ RN cơn 3 tháng cao gấp 4,45 lần, sau 6 tháng cao gấp 2,9 lần so với không giảm. Đối tượng bệnh có Euroscore II $\geq 3$ trước phẫu thuật, nguy cơ RN gấp 9,8 lần. Đối tượng bị ĐTĐ2 ít bị RN sau phẫu thuật thời điểm 6 tháng. Khác với nhận định này tác giả Tatsuishi (2015), đường máu cao sau phẫu thuật dự báo nguy cơ xuất hiện RN sau phẫu thuật với điểm cắt là $180 \mathrm{mg} / \mathrm{dl}(9,9 \mathrm{mmol} / \mathrm{l})$ không phân biệt tiền sử tiểu đường trước đó. Tỉ lệ RN cao nhất của chúng tôi chỉ có $17,2 \%$ và chúng tôi chỉ xét đối tượng bênh nhân có tiền sử ĐTĐ II hay không để phân tích, khác với đường máu cao sau phẫu thuật của tác giả Tatsuishi.

Liên quan từng chỉ số BTNT giảm đối với nguy cơ RN sau phẫu thuật cũng khác nhau (bảng 6, bảng 7 và 8). Bệnh nhân có một trong các chỉ số BTNT giảm trước phẫu thuật có nguy cơ xuất hiện RN (kéo dài $\geq 24$ giờ) sau 7 ngày tăng gấp $6-40$ lần $(p<0,05)$. Chỉ số SDANN và SDNN giảm có giá trị liên quan xuất hiện RN (kéo dài $\geq 24$ giờ) cao nhất (gấp $28-40$ lần). Bệnh nhân có các chỉ số ASDNN, rMSSD, SDNN, SDANN giảm trước phẫu thuật đều có nguy cơ xuất hiện RN (kéo dài $\geq 24$ giờ) sau 3 tháng gấp 4 - 18 lần so với bệnh nhân không có giảm BTNT trước phẫu thuật. Chỉ số SDNN giảm có giá trị liên quan xuất hiện RN (kéo dài $\geq 24$ giờ) cao nhất gấp 18 lần. Bệnh nhân có các chỉ số ASDNN, SDNN, SDANN giảm trước phẫu thuật, nguy cơ xuất hiện RN (kéo dài $\geq 24$ giờ) sau 6 tháng tăng gấp $4-9$ lần, chỉ số SDNN giảm có giá trị liên quan cao nhất (9 lần). Kết quả nghiên cứu của chúng tôi cũng cho thấy sự liên quan của các chỉ số ASDNN, rMSSD, SDNN, SDANN có khác biệt giảm hơn ở bệnh nhân RN sau phẫu thuật 1 tuần $(p<0,05)$. Sau 3 tháng phẫu thuật chỉ số SDANN thấp hơn có sự khác biệt ở bệnh nhân $R N(p<0,05)$. Sau 6 tháng phẫu thuật chì số SDNN giảm có sự khác biệt ở bệnh nhẩn RN $(p<0,05)$. Như vậy, ở bệnh nhân bệnh ĐMV mạn tính có BTNT giảm trước phẫu thuật là yếu tô nguy cơ xuất hiện RN mới sau phẫu thuật CNCV.

\section{KẾT LUÂN}

Sau phẩu thuật cầu nối chủ vành, tỉ lệ rung nhĩ mới xuất hiện là $13,7 \%-17,2 \%$ theo dõi đến 6 tháng. Tî lệ biến thiên nhịp tim giảm trước phẫu thuật là $28,6 \%$, đây được xem là yếu tố nguy cơ xuất hiện rung nhĩ mới sau phẫu thuật câuu nối chủ vành.

\section{TÀI LIÊU THAM KHẢO}

1. Gerhard Hindricks, Tatjana Potpara, Nikolaos Dagres et al (2020), "Guidelines for the diagnosis and management of atrial fibrillation developed in collaboration with the European Association for Cardio-Thoracic Surgery (EACTS)", European Heart Journal, 00: pp. 1-116.

2. Electrophysiology Developed in Collaboration with the North American Society for Pacing And (1999), "ACC/AHA Guidelines for Ambulatory Electrocardiography ", J Am Coll Cardiol, Vol. 34(No. 3): pp. 912-948.

3. Tatsuishi W., Adachi H., Murata M. et al (2015), "Postoperative hyperglycemia and atrial fibrillation after coronary artery bypass graft surgery", Circ J, 79(1): pp. 112-8.

4. Kertai M. D., Li Y. J., Ji Y. et al (2015), "Genome-wide association study of new-onset atrial fibrillation after coronary artery bypass grafting surgery", Am Heart J, 170 (3): pp. 580-90 e28.

5. Takeshi Kinoshita, Tohru Asai, Takako Ishigaki et al (2011), "Preoperative Heart Rate Variability Predicts AtrialFibrillation After Coronary Bypass Grafting", Ann Thorac Surg, 91: pp. 1176-82.

6. Lombardi F., Colombo A., Basilico B. et al (2001), "Heart rate variability and early recurrence of atrial fibrillation after electrical cardioversion", J Am Coll Cardiol, 37(1): pp. 157-62.

7. Ashes C. M., Yu M., Meineri M. et al (2014), "Diastolic dysfunction, cardiopulmonary bypass, and atrial fibrillation after coronary artery bypass graft surgery", $\mathrm{Br}]$ Anaesth, 113(5): pp. 815-21.

8. Schulman S., Cybulsky I. and Delaney J. (2015), "Anticoagulation for stroke prevention in new atrial fibrillation after coronary artery bypass graft surgery", Thromb Res, 135(5): pp. 841-5. 